\title{
LA NUPCIALIDAD EN TIERRA DE CAMPOS LEONESA EN EL SIGLO XVIII
}

\author{
Francisco Javier LAGARTOS PACHO \\ Universidad de León
}

\begin{abstract}
RESUMEN: Estudio y análisis, mediante la utilización de los registros parroquiales de bautismo y matrimonios, de los diferentes temas relacionados con la nupcialidad, su importancia en la formación, constitución y consolidación del matrimonio y las implicaciones que la nupcialidad tiene sobre los índices de fecundidad, analizando la influencia de las estructuras sociales y económicas en el comportamiento del parámetro demográfico de la nupcialidad, a lo largo del siglo XVIII en Tierra de Campos Leonesa (Comarca de Sahagún, León).

PALABRAS CLAVE: Nupcialidad, fecundidad, registros parroquiales, Tierra de Campos Leonesa, Sahagún, Siglo XVIII.

ABSTRACT: Study and analysis, by means of the use of the parochial registrations of baptism and marriages, of the different topics related with the, their importance in the formation, constitution and consolidation of the wedlock and the implications that the rates of marriage has on birth rates, analyzing the influence of the social and economic structures based on the demographic parameter of the rates of marriage, along the $18^{\text {th }}$ century in Tierra de Campos Leonesa (District of Sahagún, León).
\end{abstract}

KEYWORDS: Rates of marriage, birth rates, parochial registrations, Tierra de Campos Leonesa, Sahagún, century.

Para entender el comportamiento de una sociedad debemos de analizar los datos relativos a la nupcialidad, como uno de los parámetros demográficos más importantes dentro de la formación, constitución y consolidación del matrimonio. Las implicaciones de la nupcialidad sobre los índices de fecundidad eran muy importantes para las Sociedades del Antiguo Régimen, pues las pautas que determinaban el acceso al matrimonio regulaban tanto la proporción de casados como la duración del matrimonio y la vida fértil de las parejas ${ }^{1}$. Así la extensión del celibato, la edad de las mujeres en el primer matrimonio, la viudez y la frecuencia de las segundas nupcias, eran los mecanismos para controlar la

\footnotetext{
${ }^{1}$ LANZA GARCía, R. (1991). La población y el crecimiento económico de Cantabria en el Antiguo Régimen. Madrid, p. 308.
} 
fecundidad en aquellas sociedades, en palabras de Chaunu, P. la "verdadera arma anticonceptiva" en la Europa moderna. Pero además actuaba por causas más complejas que las puramente demográficas, como por ejemplo, en las regiones donde el trabajo dependía del acceso a la tierra por medio de la herencia familiar con lo que la restricción del acceso al matrimonio podía ser el resultado de una conducta dirigida a evitar una elevada descendencia que llevaría a fragmentar en exceso las propiedades haciendo peligrar la continuidad social y económica del sistema.

Para realizar esta tarea hemos seguido el llamado método de reconstrucción de familias, iniciado hace años por la historiografía francesa ${ }^{2}$, con el cual, mediante una serie de fichas, llegamos a interrelacionar una amplia cantidad de información referente a cada una de las familias analizadas. A pesar de todo nos encontramos con algunos problemas a la hora de enfrentarnos a los registros parroquiales ${ }^{3}$.

\section{LA TASA BRUTA DE NUPCIALIDAD.}

El primero de los parámetros que debemos conocer cada vez que nos enfrentamos a un estudio sobre el matrimonio es la tasa bruta de nupcialidad ${ }^{4}$. Las tasas brutas de nupcialidad de 1752 siguen los mismos parámetros de otras zonas leonesas como la montaña noroccidental donde la tasa es de 10,1 por mil ${ }^{5}$. Esta elevada nupcialidad es debido al alto porcentaje de matrimonios en segundas nupcias que tendrán lugar a partir de la segunda mitad del siglo XVIII ${ }^{6}$.

${ }^{2}$ Henry, L. (1983). Manual de demografia Histórica. Barcelona. Este método fue rápidamente puesto en práctica por el profesor Antonio Eiras Roel.

${ }^{3}$ Los pueblos que se han elegido han sido los de San Pedro de Valderaduey, Arenillas de Valderaduey y Vallecillo, todos ellos con unos archivos parroquiales completos y en perfecto estado de conservación. De ellos se han extraídos, mediante unas fichas tipo, todos los datos demográficos referentes a cada uno de los matrimonios que se realizaron en dichas localidades. Además, también nos interesamos por aquellos que se efectuaron en otras poblaciones pero que desarrollaron su vida conyugal en los pueblos seleccionados con anterioridad, por lo que en estos casos nos faltará la fecha de realización del matrimonio con un total aproximado de 700 fichas reconstruidas.

${ }^{4}$ Viene de dividir el número de matrimonios que tuvieron lugar durante un año entre la población media de ese mismo año. El resultado se dará en tanto por mil. Para realizar estos cálculos se suele coger la media de matrimonios del quinquenio en torno al cual se realizó el censo que nos sirve como referencia.

5 Pérez Álvarez, M.J. (1996). La montaña noroccidental leonesa en la Edad Moderna. Universidad de León, p. 257.

${ }^{6}$ Ver cuadro 19. Llegan a alcanzar los matrimonios en $2^{a}$ nupcias en la segunda mitad de la centuria el $31,8 \%$ del total de los matrimonios. 
Cuadro 1. Tasa bruta de nupcialidad (tantos por mil).

\begin{tabular}{cc}
\hline Fecha & Tasa \\
\hline 1752 & 10,25 \\
1787 & 7,7 \\
\hline
\end{tabular}

FuENTE: Archivos Parroquiales, Catastro de la Ensenada y Censo de Floridablanca.

Cuadro 2. Edad media cónyuges. $1^{\mathrm{a}}$ nupcias. 1700-1820.

\begin{tabular}{lcc}
\hline & SMAN $^{7}$ & Reconstrucción Familias $^{8}$ \\
\hline Varones & 24,1 & 23,8 \\
Hembras & 21,8 & 21,5 \\
\hline
\end{tabular}

FuENTE: Archivos Parroquiales de San Pedro de Valderaduey, Arenillas y Vallecillo.

\section{EDAD DE LOS CÓNYUGES AL MATRIMONIO.}

La edad al matrimonio ha sido uno de los aspectos que siempre ha preocupado a la hora de formar un nuevo matrimonio por las repercusiones que este hecho puede tener para su futuro. La propia Iglesia Católica, una de las principales instituciones reguladoras de la familia, nos dice que una de las condiciones imprescindibles, entre otras, que ha de tener el nuevo matrimonio es "que sus edades no sean muy desiguales" ", Este interés por conocer dicho parámetro de la nupcialidad nos lleva a adentrarnos en el método de la reconstrucción de familias, que pasa a ser un requisito imprescindible en el estudio de la distribución por edades de los primeros matrimonios. La edad de los recién casados no viene en las actas de matrimonio, ya que en el ritual romano de 1614 no lo exigía, por lo que la reconstrucción de familias ayuda a conocer la edad de buena parte de los recién casados porque su fecha de nacimiento se conoce a través de la ficha familiar de sus padres ${ }^{10}$. El conocimiento de la edad de acceso al matrimonio es un aspecto muy importante,

${ }^{7}$ El demógrafo británico John Hajnal ideo un método para la estimación de la edad media de acceso al matrimonio utilizando la proporción de solteros por cada una de las edades. Además nos permite un análisis de la nupcialidad para aquellas poblaciones para las que no existe un registro adecuado de matrimonios o donde el cálculo de la edad al matrimonio sería muy laborioso. Vid. Rowland, R. (1987). "Mortalidad, movimientos migratorios y edad de acceso al matrimonio en la Península Ibérica”. Boletín de la Asociación de demografía histórica, V, № 3. Madrid, p. 41.

${ }^{8}$ El método SMAN permite que se hagan comparaciones con los resultados obtenidos por el método de reconstrucción de familias con base en los registros parroquiales. Vid. RowLAND, R. (1987). "Mortalidad, movimientos migratorios y edad..." op. cit. Pp. 41.

9 Arbiol, A. (1770). La Familia regulada en la Sagrada Escritura. Madrid, pp. 485-486.

${ }^{10}$ Henry, L. (1983). Manual de demografia histórica. Barcelona, pp. 186-187. 
sobretodo en la mujer, porque este dato influirá en otros parámetros como la fecundidad y la natalidad ${ }^{11}$, que a su vez tiene mucho que ver con la herencia y la distribución de las propiedades entre los hijos.

Según el Cuadro 2, la edad media de acceso al matrimonio entre los varones es de 23,8 años y entre las mujeres es de 21,5 años por lo que hay una diferencia de algo más de 2 años entre las edades de ambos sexos, que la sitúan como una de las zonas de la provincia de León donde la diferencia de edad entre sexos es mayor ${ }^{12}$. Estas tempranas edades de acceso al matrimonio ocasionarán una elevada fecundidad y natalidad que condicionará las futuras actuaciones en esta zona. Los valores de la edad al matrimonio de la mujer son algo inferiores si los comparamos con el conjunto del Noroeste de España y el Cantábrico que superaba los 25 años de edad mientras que en Castilla la Vieja, Aragón y Cataluña cambiaban de estado a los 23 años y a los 22 al sur del Sistema Central. La edad del varón, también es algo inferior a lo que nos encontramos en el resto de la península, con valores que rondan los 24-25 años de edad ${ }^{13}$. Así vemos como en la zona Navarra, entre 1640 y 1819 , la edad media del varón es de 24,7 años y la de la mujer es de 22,5 años $^{14}$, en Xallas donde la media es para el hombre de 22,6 años y para la mujer de 23,9 años $^{15}$, en la zona agrícola del Salnés las edades oscilan entre los 23,3 y 21,1 para

11 "Su importancia radica en su directa repercusión en el índice de fecundidad". Vid. BARREIRO Mallón, B. (1973). La jurisdicción de Xallas a lo largo del siglo XVIII. Población, sociedad y economía. Santiago. La edad al matrimonio es, de todas las variables que regulan la fecundidad, la que produce unos mayores efectos acumulativos, aunque la esperanza de vida de algunos de los efectivos podía limitar la duración del matrimonio. Vid. LANZA GARCíA, R. La población y el crecimiento... op. cit. p. 308.

12 En otros ámbitos leoneses como la montaña noroccidental se dan unos valores muy superiores: varón 26,5 y hembra 25,9, por lo que se califica como un matrimonio tardío, aunque aquí la diferencia entre ambos sexos es menor que en nuestro caso. Vid. Pérez Álvarez, M.J. (1996). La montaña noroccidental leonesa en la Edad Moderna. Universidad de León, p. 257. En otros ámbitos como las tierras de la Bañeza en las zonas de transición (secano) se sitúan en los 23 años para los varones y 21,6 años para las mujeres, valores bastante parecidos que los de nuestra zona de estudio debido a que los condicionantes económicos son similares entre ambas zonas. RUBIO PÉREZ, L. M. (1987). La Bañeza y su tierra, (1650-1850). Un modelo de sociedad rural leonesa. Universidad de León, p.108.

${ }^{13}$ LANZA GARCíA, R. (1991). La población y el crecimiento económico... op. cit. pp. 311-312.

${ }^{14}$ FloRistán IMízCOZ, A. (1982). La merindad de Estella durante la Edad Moderna: los hombres y la tierra. Pamplona, p. 99.

15 BARREIRO, MALlón, B. (1977). "Interior y costa: dos muestras de una estructura demográfica antigua en la Galicia rural”. Fuentes y Métodos. Santiago, p.162. 
los hombres y 24,6 y 21,6 años para las mujeres ${ }^{16}$ y en Segovia y Cáceres donde las edades de la mujer son de $19-20$ y 20,5 años y las del hombre son de 22 y 23,5 años, respectivamente ${ }^{17}$.

Cuadro 3. Edad media cónyuges. $2^{\mathrm{a}}$ nupcias. 1700-1820.

\begin{tabular}{lcc}
\hline & Sman & Reconstrucción familias \\
\hline Varones & 40,1 & 38,8 \\
Hembras & 31,9 & 31,5 \\
\hline
\end{tabular}

FuENTE: Archivos Parroquiales de San Pedro de Valderaduey, Arenillas y Vallecillo.

Cuadro 4. Edad al matrimonio. $1^{\mathrm{a}}$ nupcias. 1700-1800.

\begin{tabular}{crrrrrr}
\hline \multirow{2}{*}{ Edad } & \multicolumn{2}{c}{$1700-1749$} & \multicolumn{2}{c}{$1750-1800$} & \multicolumn{2}{c}{ Total } \\
\cline { 2 - 7 } & Varón & Hembra & Varón & Hembra & Varón & Hembra \\
\cline { 2 - 7 } & $\%$ & $\%$ & $\%$ & $\%$ & $\%$ & $\%$ \\
\hline-20 & 23,1 & 35,8 & 18,3 & 27,6 & 20 & 30,7 \\
$20-24$ & 38,5 & 45,3 & 50,7 & 57,5 & 46,4 & 52,9 \\
$25-29$ & 33,3 & 15,1 & 19,7 & 10,3 & 24,5 & 12,1 \\
$30-34$ & 2,6 & 3,8 & 7 & 4,6 & 5,5 & 4,3 \\
$35-39$ & 2,6 & 0 & 4,2 & 0 & 3,6 & 0 \\
+40 & 0 & 0 & 0 & 0 & 0 & 0 \\
\hline Total & 100 & 100 & 100 & 100 & 100 & 100 \\
\hline
\end{tabular}

FuENTE: Archivos Parroquiales de San Pedro de Valderaduey, Arenillas y Vallecillo.

La edad media en $2^{\mathrm{a}}$ nupcias es de 38,8 años para los varones y 31,5 años para las mujeres ${ }^{18}$. Vuelve a ser el varón el que supere en edad a la hembra ampliándose la diferencia entre sexos hasta superar los 7 años, lo que nos indican que las mujeres que se casan en $2^{\mathrm{a}}$ nupcias realizaron su primer matrimonio a edades muy tempranas ${ }^{19}$ y con un cónyuge de edad muy elevada por lo que, cuando se produjo

${ }^{16}$ Pérez García, J.M. (1979). Un modelo de sociedad rural del Antiguo Régimen en la Galicia costera: la península del Salnés. Santiago, p. 197.

${ }^{17}$ PÉrez MoredA, V. (1986). "Matrimonio y familia: algunas consideraciones sobre el modelo matrimonial español en la Edad Moderna". B.A.D.H., año IV, $\mathrm{n}^{\mathrm{o}} 1$, p. 10 y RodRíGUEZ CANCHO, (1981), p. 177.

${ }^{18}$ El dato del hombre es similar al que se produce en la montaña noroccidental leonesa que es de 38,5 años, sin embargo, el de la mujer en Tierra de Campos es superior en casi tres años al que se produce en la montaña. Vid. PÉRez Álvarez, M.J.). La montaña noroccidental leonesa en la Edad Moderna. Universidad de León, pp. 273-274.

${ }^{19}$ Esto lo podemos constatar en los cuadros 4 y 9. 
la muerte del marido, son viudas bastante jóvenes y además están aún en periodo fértil, por lo que éste será un factor que condicione la fecundidad y las relaciones de parentesco con la entrada de nuevas personas con derecho sucesorio en las escasas haciendas de Tierra de Campos.

Según el Cuadro 4, la edad al matrimonio que predomina entre los cónyuges a lo largo del siglo XVIII es de $20-24$ años en los varones $(46,4 \%)^{20}$ y entre las mujeres es también de 20-24 años $(52,9 \%)^{21}$. A pesar de estos datos, podemos decir que el matrimonio en el caso de la mujer es precoz, ya que, más del $85 \%{ }^{22}$ de las mujeres tiene menos de 25 años cuando se casan y entre los hombres este dato baja hasta el $66,4 \%$. Además, entre los hombres, se extiende la edad de matrimonio hasta los 39 años $(3,6 \%)$ y entre las mujeres no pasan de los 34 años en ninguno de los casos. Además un 1/3 del total de éstas tienen menos de 20 años al contraer matrimonio, dato es similar al que se produce en La Bañeza donde el $25 \%$ de las mujeres tienen menos de 20 años cuando cambian de estado ${ }^{23}$. En la primera mitad

${ }^{20}$ Dato inferior del que se produce en tierras de la Bañeza que sube al $60 \%$ entre los varones. Rubio Pérez, L. M. (1987). La Bañeza y su tierra, (1650-1850). Un modelo de sociedad rural leonesa. Universidad de León, p.108. Dato muy inferior si lo comparamos con el más alto de la provincia de León, este es el de la montaña noroccidental leonesa donde solo 4,5 de cada 10 se casan antes de los 25 años. Vid. Pérez Álvarez, M.J. (1996). La montaña noroccidental leonesa... op. cit. p. 259.

21 Esto mismo sucede en el Bierzo. Vid. Bartolomé, Bartolomé, J.M. (1996). Vino y Viticultores en el Bierzo. Sociedad y estructuras económicas durante el siglo XVIII. Universidad de León, pp. 271-272. También en las tierras de La Bañeza, aunque dentro de esta zona se encuentran diferencias entre las zonas de secano y de regadío donde, en ésta última, la precocidad es aún mayor, vid. Rubio PÉRez, L. M. (1987). La Bañeza y su tierra... op. cit. p. 106. En la montaña leonesa solo 4,7 de cada 10 mujeres se casan antes de los 25v años. Vid. Pérez Álvarez, M.J. (1996). La montaña noroccidental... Op. cit. p. 259. Este dato es muy similar al que se produce en otras zonas de España, vid. FloRistan, A. (1982). La Merindad de Estella en la Edad Moderna: los hombres y la tierra. Pamplona, pp. 100-101.

${ }^{22}$ Además, podemos decir que el número de mujeres que se casan con menos de 25 años es muy inferior en el Bierzo. En otras zonas como la Bañeza las mujeres que se casan con menos de 25 años son el $60 \%$ del total a lo largo del siglo XVIII, dato inferior del que se produce en nuestra zona que es del $80 \%$. Este dato es igualado con las zonas ribereñas de la Bañeza que, debido a su especial configuración económica, posibilita matrimonios más precoces. RuBIO PÉREZ, L. M. (1987). La Bañeza y su tierra... op. cit. p. 106. Pero este dato es bastante similar a lo que se produce en las zonas gallegas de Xallas. Vid. BARreiro, B. (1973). La jurisdicción de Xallas ... op. cit. p.162.

${ }^{23}$ Destaca el periodo 1721-1760 donde el dato se acerca al 32-35\%. RuBio PÉREZ, L. M. (1987). La Bañeza... op. cit. p. 106. Por el contrario, en la zona noroccidental montañosa de la provincia de León la edad al matrimonio es mucho más elevada en ambos sexos predominando el grupo 25-29 con un 34,1\% de los casos. Vid. Pérez Álvarez, M.J. (1996). La montaña noroccidental leonesa... op cit. p. 258. 
de siglo, la edad predominante es de 20-24 años con un 45\% para las mujeres y un $38 \%$ para los varones ${ }^{24}$. Este elevado dato de precocidad en la mujer traería consigo un aprovechamiento al máximo de su capacidad reproductora ${ }^{25}$. En la segunda mitad de siglo, vemos que se afianza la edad de 20-24 con más de la mitad de los casos en ambos sexos (siempre superior entre las mujeres) ${ }^{26}$. Por otro lado, disminuye el porcentaje en el grupo de edad inferior a 20 años en los dos $\operatorname{sexos}^{27} \mathrm{y}$ aumenta entre los grupos de mayor edad. Este retraso de la edad al matrimonio también se produce en la Bañeza ${ }^{28}$ y en la zona berciana ${ }^{29}$. Además, a lo largo del siglo XVIII, ninguna mujer se casa con más de 35 años y ningún hombre con más de 40 años.

${ }^{24}$ Si comparamos estos datos con los del Bierzo con un $48 \%$ entre las mujeres y el $25 \%$ en ese mismo intervalo para los hombres. Vid. BARTOLOMÉ, BARTOLOMÉ, J.M. (1996). Vino y Viticultores en el Bierzo... Op. cit. pp. 271-272. En la montaña noroccidental de la provincia de León vemos como la edad al matrimonio que predomina en ambos sexos es de 25-29 años. Vid. PÉrez Álvarez, M.J. (1996). La montaña noroccidental leonesa... op. cit. pp. 258-260.

${ }^{25}$ En otras zonas, como en el Bierzo, también predomina la edad al matrimonio en el grupo 20-24 años entre las mujeres aunque con unos porcentajes algo superior en el caso de la mujer con un $48 \%$ y bastante inferiores en el caso del hombre (25\%) entre los que predomina el grupo 25-29 con un 36,4\% superior a lo que se daba en Tierra de Campos. En la zona de Tierra de Campos Leonesa se produce un mayor equilibrio entre sexos en la edad al matrimonio de lo que ocurre en la zona berciana, pero la tendencia en ambas zonas es a que la edad del marido sea mucho mayor que la de la mujer. Vid. BARTOlOMÉ, BARTOlomé, J.M. (1996). Vino y Viticultores en el Bierzo... op. cit. pp. 271.

${ }^{26}$ En la segunda mitad del siglo la edad al matrimonio en la montaña noroccidental leonesa se reduce predominando el grupo de edad 20-24, aunque es más pronunciado entre la mujer que llega a adelantar en dos años al hombre. Vid. Pérez Álvarez, M.J. La montaña noroccidental leonesa... op. cit. p. 260.

${ }^{27}$ En la montaña noroccidental leonesa el número de varones que se casan con menos de 20 años se reducen a un simbólico $3,7 \%$ mientras que el de las mujeres aumenta hasta el $22,2 \%$, valor inferior al dato de la zona de Tierra de Campos pero más aproximado de lo que sucede en el caso de los varones. A pesar de todo podemos decir, que en ambos zonas la edad al matrimonio se retrasa en la segunda mitad del siglo XVIII.

${ }^{28}$ Rubio PÉRez, L. M. (1987). La Bañeza... op. cit. p.108.

${ }^{29}$ Se aprecia que la edad al matrimonio en el Bierzo ha crecido de manera considerable a diferencia de lo que ocurre en la comarca de Sahagún donde se consolida la edad de 20-24 años. Por otro lado, en la zona berciana las edades de los grupos superiores se consolidad o incluso crecen en algunos de sus parámetros. Vid. BARTOLOMÉ, BARTOLOMÉ, J.M. (1996). Vino y Viticultores ... op. cit. pp. 271-272. 
Cuadro 5. Total edad al matrimonio. $2^{\mathrm{a}}$ nupcias. $1700-1800$.

\begin{tabular}{crrrrrr}
\hline & \multicolumn{2}{c}{$1700-1749$} & \multicolumn{2}{c}{ Total } \\
\cline { 2 - 7 } Edad & Varón & Hembra & Varón & Hembra & Varón & Hembra \\
\cline { 2 - 7 } & $\%$ & $\%$ & $\%$ & $\%$ & $\%$ & $\%$ \\
\hline \hline-20 & 0 & 20 & 0 & 0 & 0 & 6,3 \\
$20-24$ & 28,6 & 40 & 0 & 18,2 & 9,1 & 25 \\
$25-29$ & 0 & 20 & 13,3 & 18,2 & 9,1 & 18,8 \\
$30-34$ & 14,3 & 0 & 20 & 18,2 & 18,2 & 12,5 \\
$35-39$ & 14,3 & 0 & 20 & 27,3 & 18,2 & 18,8 \\
+40 & 42,9 & 20 & 46,7 & 18,2 & 45,5 & 18,8 \\
\hline \hline Total & 100 & 100 & 100 & 100 & 100 & 100 \\
\hline \hline
\end{tabular}

FUENTE: Archivos Parroquiales de San Pedro de Valderaduey, Arenillas y Vallecillo.

Por lo que respecta a la edad de los esposos en matrimonio de $2^{\mathrm{a}}$ o más nupcias, podemos destacar que entre los varones predomina una edad mayor de 40 años $(45,5 \%)$ muy superior a la que registran las mujeres donde predomina el grupo de 20-24 años.

Además, más del $80 \%$ de los varones se casan en $2^{\mathrm{a}}$ nupcias con más de 30 años, porcentaje que baja al 50\% entre las mujeres. Por otro lado, hay un escaso número de mujeres que se casen en $2^{\mathrm{a}}$ nupcias con menos de 20 años $(6,3 \%)$, dato éste que desaparece cuando hablamos de los varones. A primera vista, no encontraríamos una explicación a este fenómeno relativo a la temprana edad en las segundas nupcias de las mujeres.

Cuadro 6. Edad al matrimonio. $2^{\mathrm{a}}$ nupcias. 1700-1800.

$$
1700-1749 \quad 1750-1800 \quad \text { Total }
$$

\begin{tabular}{|c|c|c|c|c|c|c|c|c|c|c|c|c|}
\hline \multirow{4}{*}{ Edad } & \multicolumn{4}{|c|}{$1700-1749$} & \multicolumn{4}{|c|}{$1750-1800$} & \multicolumn{4}{|c|}{ Total } \\
\hline & \multicolumn{2}{|c|}{ Viudo-Soltera } & \multicolumn{2}{|c|}{ Viuda-Soltero } & \multicolumn{2}{|c|}{ iudo-Soltera } & \multicolumn{4}{|c|}{ Viuda-Soltero Viudo-Soltera } & \multicolumn{2}{|c|}{ Viuda-Soltero } \\
\hline & $\begin{array}{l} \\
\end{array}$ & $H$ & $V$ & $H$ & V & $H$ & V & $H$ & V & $H$ & V & H \\
\hline & $\%$ & $\%$ & $\%$ & $\%$ & $\%$ & $\%$ & $\%$ & $\%$ & $\%$ & $\%$ & $\%$ & $\%$ \\
\hline-20 & 0 & 50 & 40 & 25 & 0 & 33,3 & 0 & 0 & 0 & 37,5 & 22,2 & $\overline{9,1}$ \\
\hline $20-24$ & 0 & 25 & 40 & 50 & 0 & 25 & 50 & 14,2 & 0 & 25 & 44,4 & 27,3 \\
\hline $25-29$ & 0 & 25 & 20 & 25 & 16,7 & 33,3 & 25 & 42,8 & 12,5 & 31,3 & 22,2 & 36,4 \\
\hline $30-34$ & 25 & 0 & 0 & 0 & 25 & 8,3 & 25 & 0 & 25 & 6,3 & 11,1 & 0 \\
\hline $35-39$ & 25 & 0 & 0 & 0 & 25 & 0 & 0 & 42,8 & 25 & 0 & 0 & 27,3 \\
\hline+40 & 50 & 0 & 0 & 0 & 33,3 & 0 & 0 & 0 & 37,5 & 0 & 0 & 0 \\
\hline Total & 100 & 100 & 100 & 100 & 100 & 100 & 100 & 100 & 100 & 100 & 100 & 100 \\
\hline
\end{tabular}

, varón; $H$, hembra

Fuente: Archivos Parroquiales de San Pedro de Valderaduey, Arenillas y Vallecillo. 
Si observamos el Cuadro 6, vemos que es debido, a la siguiente circunstancia: la juventud de las viudas. Éstas se habían casado solteras y muy jóvenes, algunas con tan solo 16-18 años, pero en general más del 60\% lo hacían antes de los 25 años con hombres viudos muy mayores ${ }^{30}$, que llegaban a los 48-50 años, por lo que en el momento de enviudar las esposas seguían siendo jóvenes ${ }^{31}$.

En la primera mitad del siglo XVIII el $75 \%$ de las mujeres que se casan en $2^{\text {a }}$ nupcias lo hacen con menos de 30 años mientras que el 100\% de los hombres se casan con más de esa edad. A su vez, la mitad de las solteras que se casan con un viudo no llegan a los 20 años y el $75 \%$ no pasan de los 25 . Por otro lado, los solteros que no llegan a los 20 años son el $40 \%$ y más de la mitad de los viudos pasan de los 40 años $^{32}$. En la segunda mitad de siglo, la edad de los solteros aumenta aún más, llegando a desaparecer los matrimonios donde éste tenga menos de 20 años. Además, aumenta la edad al matrimonio de las solteras, casi el $60 \%$ se casan con más de 20 años, y de las viudas, el $42 \%$ de los matrimonios se realiza con más de 35 años $^{33}$. Relacionando estos datos con la edad del primer matrimonio $^{34}$, llegamos a la conclusión de que la elevada edad de los varones en las $1^{a}$ nupcias influye en la posterior realización de un segundo matrimonio que, cuando se lleva a la práctica, ofrece unas edades muy elevadas, al contrario de lo que ocurría con las mujeres. Si a esto le unimos que las mujeres en $2^{\mathrm{a}}$ nupcias se casan a edades más tempranas, quiere decir que éstas quedan viudas bastante jóvenes, lo que posibilita la realización de otro matrimonio, mientras que los hombres quedan viudos a edades más tardías impidiendo la realización de otra unión.

\footnotetext{
${ }^{30}$ Así lo podemos ver en el cuadro 6 donde hasta mediados de siglo la mitad de las solteras que se casaban con un viudo tenían menos de 20 años y por otro lado el $50 \%$ de los hombres viudos tenían más de 40 años.

${ }^{31}$ Ver cuadro 6 donde más del $37 \%$ de las viudas de Tierra de Campos leonesa, que se casaban con un soltero, no llegaban a los 25 años y ninguna pasaba de los 40 años.

32 En la montaña noroccidental leonesa la edad media de la soltera era de 30,2 años, la del soltero era de 25,7, la del viudo de 37,8 y la de la viuda 27,1. Vid. Pérez Álvarez, M.J. (1996). La montaña noroccidental leonesa... op. cit. p. 274.

33 Para comparar con otros ámbitos provinciales. Vid. PÉREZ ÁlvAREZ, M.J. (1996). La montaña noroccidental leonesa... op. cit. p. 274.

${ }^{34}$ Ver cuadro 2.
} 
Gráfico 1. Evolución edad al matrimonio. $1^{\mathrm{a}}$ nupcias. Varones.

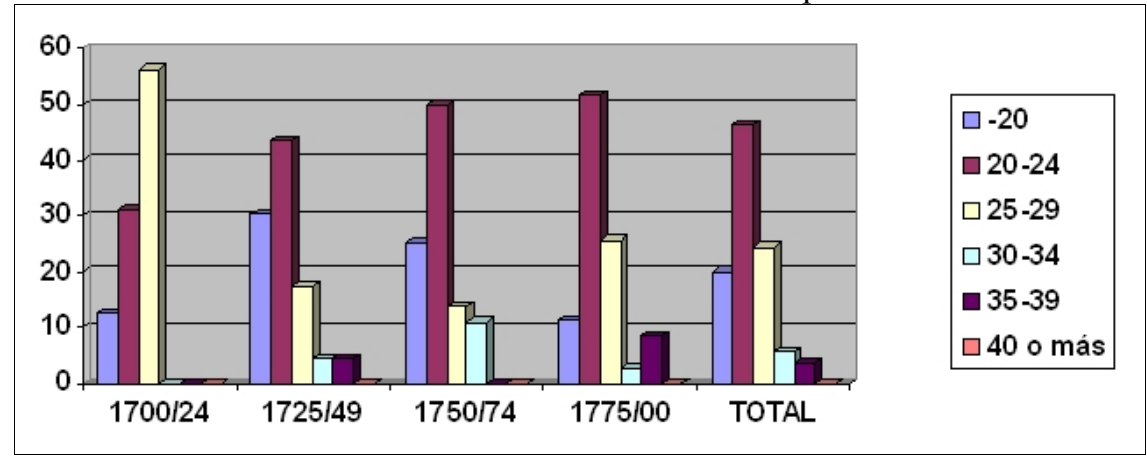

FuENTE: Archivos Parroquiales de San Pedro de Valderaduey, Arenillas y Vallecillo

Gráfico 2. Evolución edad al matrimonio. $1^{a}$ nupcias. Hembras.

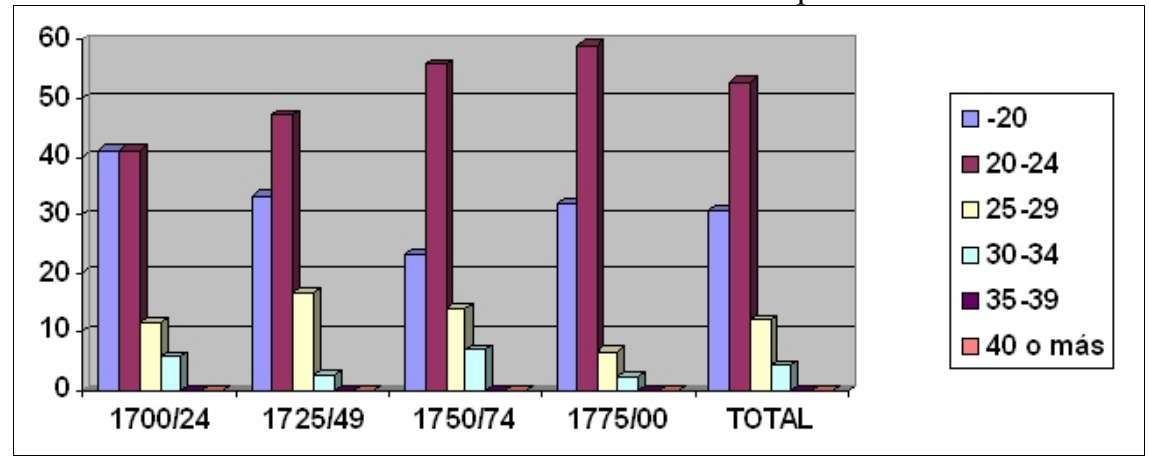

FUENTE: Archivos Parroquiales de San Pedro de Valderaduey, Arenillas y Vallecillo.

\section{RELACIÓN DE LA EDAD DE LOS ESPOSOS.}

Uno de los aspectos más interesantes cuando se estudia la conformación de los nuevos matrimonios, es analizar la relación que existe entre las edades de los esposos en el momento de la constitución del matrimonio ${ }^{35}$.

Durante el primer periodo, el $40 \%$ de todas estas mujeres que se casan con menos de 25 años lo hacen con hombres que superan esta edad con el objetivo de buscar una mayor estabilidad económica y protección que le ofrece un cónyuge, que en muchos de los casos, había heredado ya alguna de sus legitimas paterna o

${ }^{35}$ Para realizar estas tablas el número de datos se ha reducido con respecto a tablas anteriores, ya que, a diferencia de antes, ahora necesitamos tener la fecha de nacimiento de ambos esposos para que dicho dato sea aprovechable. 
materna $^{36}$. El 100\% de las mujeres menores de 20 años prefiere a hombres mayores pero que no sobrepasen los 30 años, siendo los matrimonios de edades similares escasos o inexistentes entre éstas y algo más elevados entre las que se casan a los 20-24 años (40\%). El 50\% de las mujeres que se casan entre 25-29 años lo hacen con hombre más jóvenes que ellas debido, entre otras cosas, a la disminución en el número de efectivos masculinos de edades parecidas a las de la mujer como consecuencia de la muerte. Por lo tanto, a partir de 25 años y, especialmente de los 30 años, se van igualando las edades al matrimonio de ambos cónyuges ${ }^{37}$.

Cuadro 8. Relación edades de los esposos. $1^{\mathrm{a}}$ nupcias. 1700-1800.

\begin{tabular}{|c|c|c|c|c|c|c|c|c|c|c|c|c|}
\hline \multirow{4}{*}{ Edad } & \multicolumn{6}{|c|}{$1700 / 1749$} & \multicolumn{6}{|c|}{$1750 / 1799$} \\
\hline & \multicolumn{6}{|c|}{ Edad Mujer } & \multicolumn{6}{|c|}{ Edad Mujer } \\
\hline & -20 & $0-24$ & $25-29$ & $30-34$ & $34-39$ & +40 & -20 & $20-24$ & $25-29$ & $30-34$ & $34-39$ & +40 \\
\hline & $\%$ & $\%$ & $\%$ & $\%$ & $\%$ & $\%$ & $\%$ & $\%$ & $\%$ & $\%$ & $\%$ & $\%$ \\
\hline-20 & 0 & 20 & 25 & 0 & 0 & 0 & 21,4 & 17,2 & 50 & 0 & 0 & 0 \\
\hline $20-24$ & 66,7 & 40 & 25 & 0 & 0 & 0 & 42,9 & 51,7 & 25 & 100 & 0 & 0 \\
\hline $25-29$ & 33,3 & 20 & 25 & 0 & 0 & 0 & 14,3 & 20,7 & 0 & 0 & 0 & 0 \\
\hline $30-34$ & 0 & 20 & 0 & 0 & 0 & 0 & 14,3 & 3,4 & 25 & 0 & 0 & 0 \\
\hline $35-39$ & 0 & 0 & 25 & 0 & 0 & 0 & 7,1 & 3,4 & 0 & 0 & 0 & 0 \\
\hline+40 & 0 & 0 & 0 & 0 & 0 & 0 & 0 & 3,4 & 0 & 0 & 0 & 0 \\
\hline Total & 40 & 33 & 27 & 0 & 0 & 0 & 29 & 60 & 8 & 2 & 0 & 0 \\
\hline
\end{tabular}

FuENTE: Archivos Parroquiales de San Pedro de Valderaduey, Arenillas y Vallecillo

En el segundo periodo, 1750- 1799, casi el 90\% de las mujeres que se casan lo hacen con menos de 24 años, cifra superior a la primera mitad del siglo XVIII. Esta tendencia de consolidación o reducción de la edad al matrimonio se produce en algunas zonas como la montaña noroccidental leonesa, La Bañeza, etc. ${ }^{38}$, aunque en otros lugares como el Bierzo, la trayectoria es a aumentar dichas edades ${ }^{39}$. Dentro de este grupo mayoritario, casi el $70 \%$ de las mujeres se casan con menos

${ }^{36}$ En el Bierzo, las edades de los esposos son muchos mayores que las de las mujeres superando los 29 años y llegando hasta los 39 o 44 años. BARTOLOMÉ, BARTOLOMÉ, J.M. (1996). Vino y Viticultores... op. cit. pp. 273-274. Por el contrario, en la montaña noroccidental leonesa los valores son más parecidos a nuestra zona de estudio. PÉREZ ÁlvAREZ, M.J. (1996). La montaña noroccidental leonesa... op. cit. pp.263-264.

${ }^{37}$ Esto mismo no ocurre en la montaña noroccidental leonesa donde se produce un hecho bastante insólito y es que las mujeres con 35-39 años se casan con jóvenes menores de 20 años. Vid. Ibidem, p.263.

${ }^{38}$ En la montaña noroccidental leonesa pasamos de la edad de 25-29 años a los 20-24 años con un $40 \%$ de los matrimonios realizados. Ibidem, pp. 263-264.

${ }^{39}$ Vid. BARTOlOMÉ, BARTOLOMÉ, J.M. (1996). Vino y Viticultores... op. cit. pp. 273-274. 
de 24 años y con hombres de su misma edad o más jóvenes, al contrario de lo que ocurría en el primer periodo donde la edad de la mujer era inferior a la del hombre para esos grupos de edades. Las mujeres que se casan con menos de 20 años prefieren a hombres de mayor edad y las que lo hacen entre 25-29 años se casan con hombres de edades inferiores en un $75 \%$ y el resto con hombres de edades superiores, apuntando la tendencia que viene siendo habitual donde cuanto más elevada es la edad de la mujer menor es la del marido ${ }^{40}$. Cuando la mujer se casa con más 30 años lo hace con hombres mucho más jóvenes que ella, que la proporcionen el sustento económico tanto para ella como para sus hijos menores, por lo que el componente económico marcará las pautas decisorias. Además, la escasez de un mercado masculino de elevada edad la obliga a ello ${ }^{41}$. Por otro lado, el hombre se casará con mujeres mucho más jóvenes que él con el objetivo de aprovechar su etapa fértil y proporcionarle el mayor número de hijos que pasaban a ser un capital humano importante para la economía familiar.

Cuadro 9. Relación edades de los esposos. $2^{\mathrm{a}}$ nupcias. 1700-1800.

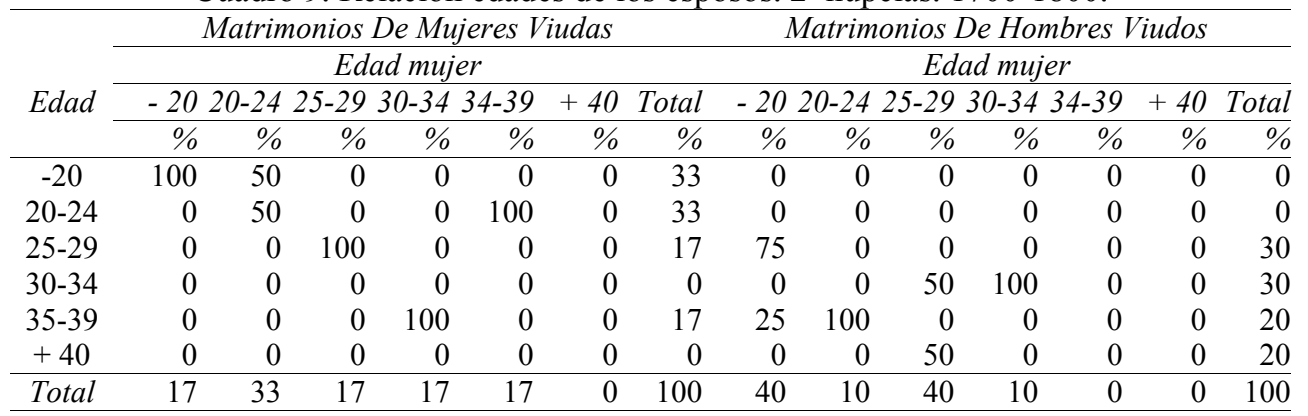

FUENTE: Archivos Parroquiales de San Pedro de Valderaduey, Arenillas y Vallecillo.

Por último, debemos de concretar la relación que existe en la edad de los cónyuges en las segundas nupcias. Entre los hombres viudos es norma buscar a

40 Estos valores son distintos si los comparamos con zonas como la montaña noroccidental leonesa donde las mujeres comprendidas con edades entre 25-29 años en un 50\% se casan con hombres de menor edad y tan solo un $20 \%$ (cifra algo inferior a la de nuestra zona) lo hacen con hombres de mayor edad, siendo la diferencia en años iguala la de nuestra zona. Vid. PÉREZ Álvarez, M.J. (1996). La montaña noroccidental leonesa... op. cit. pp.264-265.

${ }^{41}$ Esto mismo, aunque de forma mucho más acusada, se repite en otras zonas como la montaña noroccidental leonesa donde el $100 \%$ de los casos de las mujeres se casan con hombres de igual o inferior edad a ellas. Vid. Íbidem, pp. 264. 
esposas solteras más jóvenes que él ${ }^{42}$, aspecto éste que no está tan claro cuando es la mujer quien está viuda y decide casarse con un hombre soltero. Ésta prefiere un hombre de edad similar a la suya o incluso mayor. El inconveniente que tenemos es lo reducido de la muestra, que en el caso de los hombres apunta la tendencia generalizada, en la cual, los viudos/as buscan cónyuges más jóvenes ${ }^{43}$, esta tendencia no está tan marcada entre las viudas que acceden a un segundo matrimonio ${ }^{44}$. Aunque con alguna matización, que en mayor medida está debida a lo escasa representatividad de la muestra, se confirma el comportamiento que Cabourdin encontró en Meulan ${ }^{45}$ : cuando la esposa enviuda ha de conformarse con un esposo de mayor edad.

Cuadro 10. Media de la diferencia real de edad. 1700-1799.

\begin{tabular}{|c|c|c|c|c|c|c|c|c|}
\hline & \multicolumn{4}{|c|}{$1^{a}$ Nupcias } & \multicolumn{4}{|c|}{$2^{a}$ Nupcias } \\
\hline & \multicolumn{2}{|c|}{ Hombre - mujer } & \multicolumn{2}{|c|}{ Mujer-hombre } & \multicolumn{2}{|c|}{ Hombre- mujer } & \multicolumn{2}{|c|}{ Mujer-hombre } \\
\hline & $1700 / 49$ & $1750 / 99$ & $1700 / 49$ & $1750 / 99$ & $1700 / 49$ & $1750 / 99$ & $1700 / 49$ & $1750 / 99$ \\
\hline Media & 6,3 & 4,6 & 4 & 3,4 & 9,2 & 11,2 & 0 & 8,3 \\
\hline Media periodo & \multicolumn{2}{|c|}{5,4} & \multicolumn{2}{|c|}{3,7} & \multicolumn{2}{|c|}{10,2} & \multicolumn{2}{|c|}{8,3} \\
\hline Total media & \multicolumn{4}{|c|}{4,5 años } & \multicolumn{4}{|c|}{9,25 años } \\
\hline
\end{tabular}

FuENTE: Archivos Parroquiales de San Pedro de Valderaduey, Arenillas y Vallecillo.

Como vemos, la diferencia media de edad entre los cónyuges es de 4,5 años a lo largo de todo el siglo, elevándose a 9,25 años cuando se trata de matrimonios en $2^{\mathrm{a}}$ nupcias $^{46}$. Esto nos demuestra que la ruptura de los matrimonios lo que origina son nuevas uniones donde la diferencia de edad se hace mucho más acusada.

Analizando por periodos, nos damos cuenta que en los matrimonios de $1^{\text {a }}$ nupcias la diferencia de edad del hombre con respecto a la mujer en el momento del matrimonio es de casi 2 años a favor de éste. Podemos comprobar que hay una tendencia a ir reduciendo las diferencias en la edad, esta reducción más acusada entre los hombres que descienden en casi 2 años frente a las mujeres que tan solo lo hacen en 0,6 años. A pesar de todo, los esposos seguirán siendo, a finales de siglo,

${ }^{42}$ Lo mismo sucede en la Bañeza donde de 58 casos analizados 32 se casan con mujeres más jóvenes. Vid. PÉrez RuBIo, L M. (1987). La Bañeza y su tierra. 1650-1850. Universidad de León, pp.123-124.

${ }^{43}$ Cabourdin, G. (1978). "Le remarriage". A.D.H., p. 320.

44 En otras zonas como La Bañeza tanto viudas como viudos buscan para segunda unión cónyuges más jóvenes. Vid. Pérez Rubio, L M. (1987). La Bañeza y su tierra... Op. cit. pp.123-124.

45 Cabourdin, G. (1978). "Le remarriage". A.D.H., p.321.

${ }^{46}$ Ver cuadro 10. 
los que tengan una mayor diferencia de edad con respecto a sus mujeres, 4,6 frente al 3,4, aunque ahora reducida a poco más de un año frente a los 2,3 años de principios de siglo.

Por lo que respecta a la evolución de los matrimonios en $2^{\mathrm{a}}$ nupcias, la media de la diferencia de edad con respecto a los matrimonios en $1^{\mathrm{a}}$ nupcias se dobla en ambos casos. Este aumento es algo más elevado entre las mujeres. A pesar de ello, se siguen manteniendo los 2 años de diferencia entre el varón y la hembra a lo largo de todo el siglo, 10,2 y 8,3 años respectivamente. En el caso de los hombres se produce un incremento en 2 años, alcanzando los 11,2 años de diferencia con su esposa, en la segunda mitad de siglo, lo que demuestra que los varones cada vez más se casan en segundas nupcias con mujeres más jóvenes cuyo ciclo reproductivo será mucho más amplio. A partir de mediados de siglo, la distancia entre la diferencia de edad real del hombre y la mujer aumenta hasta los 3 años, siendo la más alta de todo el periodo.

Cuadro 11. Cónyuge de mayor edad en el matrimonio.1700-1800.

\begin{tabular}{lrr}
\hline \hline Cónyuge de mayor edad & $1700-1749$ & $1750-1799$ \\
\cline { 2 - 3 } & $\%$ & $\%$ \\
\hline \hline Esposo & 75 & 66,7 \\
Esposa & 20 & 28,1 \\
Misma Edad & 5 & 5,3 \\
\hline \hline Total & 100 & 100 \\
\hline \hline
\end{tabular}

FUENTE: Archivos Parroquiales de San Pedro de Valderaduey, Arenillas y Vallecillo.

Como observamos en el cuadro 11, durante todo el siglo XVIII el cónyuge de mayor edad en el matrimonio es el marido. A pesar de ello, se produce en la segunda mitad del siglo un descenso del número de matrimonio donde el esposo es mayor y un aumento de aquellos en los que lo era la mujer, mientras que aquellos en los que ambos tenían la misma edad siguió igual a lo largo del siglo.

\section{DURACIÓN DEL MATRIMONIO.}

Este parámetro medirá el periodo que transcurre desde que una pareja contrae matrimonio hasta que se rompa por el fallecimiento de uno de ellos. Conocer este dato es importante porque nos pone de manifiesto la etapa fértil de la mujer. Si el final del matrimonio se producía después de los 45 años en la mujer, la incidencia sobre la fecundidad iba a ser menor que si lo hacía antes. Cuando era el marido la persona viuda, dicha ruptura podía generar nuevos matrimonios fértiles. 
Cuadro 12. Duración media de los matrimonios $1^{\mathrm{a}}$ nupcias.

\begin{tabular}{cc}
\hline Periodo & Duración media en años \\
\hline $1700-1724$ & 22,8 \\
$1725-1749$ & 21,5 \\
$1750-1774$ & 22,3 \\
$1775-1799$ & 21,5 \\
\hline Total Media & 22 \\
\hline
\end{tabular}

FueNTE: Archivos Parroquiales de San Pedro de Valderaduey, Arenillas y Vallecillo.

Gráfico 3. Duración media de los matrimonios. $1^{\mathrm{a}}$ nupcias.

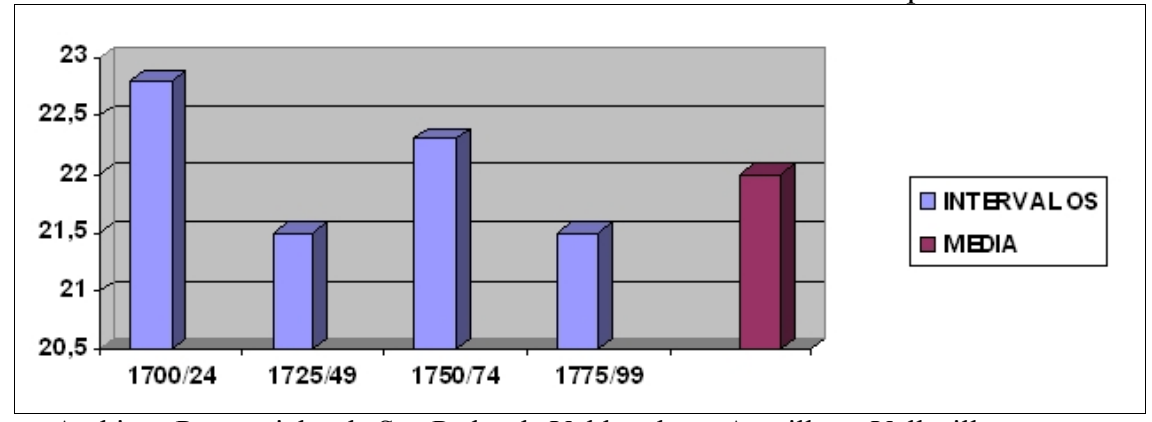

Fuente: Archivos Parroquiales de San Pedro de Valderaduey, Arenillas y Vallecillo.

Del análisis del cuadro 12 se desprende que la duración media de los matrimonios en $1^{\mathrm{a}}$ nupcias en Tierra de Campos Leonesa durante el S. XVIII es de 22 años $^{47}$, cifra que no es muy alta si la comparamos con la edad de acceso al matrimonio de la mujer que es bastante baja ( $83 \%$ de ellas se casan con menos de 24 años), por lo tanto, el motivo por el cual no se refleje esa edad temprana en la duración de los matrimonios es debido a la tardía edad de acceso al matrimonio por parte de los hombres ${ }^{48}$. Este hecho nos explicará el elevado número de matrimonios en segundas nupcias. Desde un punto de vista evolutivo, el primer cuarto de siglo será el periodo donde se registre la mayor duración de los matrimonios con 22,8 años, descendiendo en más de un año hacia la segunda mitad de la centuria. Esta misma tendencia se produce a partir de la segunda mitad de siglo. Pero, como

${ }^{47}$ Este dato algo inferior al que se da en otras zonas leonesas cono en la montaña noroccidental leonesa que es de 23,7 años. Vid. PÉrez Álvarez, M.J. (1996). La montaña noroccidental leonesa... op. cit. p.266. En la zona de La Bañeza la duración media de los matrimonios varió poco durante el siglo XVIII situándose entre los 23 y 24 años. Vid. PÉrEZ RuBio, L M. (1987). La Bañeza... op. cit. pp.115-116.

${ }^{48}$ Ver cuadros 2 y 4. 
podemos comprobar, la tónica general es la estabilidad ${ }^{49}$ a lo largo del siglo XVIII que nos indica que no se produjeron cambios importantes en las condiciones que favorecieran una mayor longevidad matrimonial.

Cuadro 13. Duración media de los matrimonios. $2^{\mathrm{a}}$ nupcias.

\begin{tabular}{cc}
\hline Periodo & Duración media en años \\
\hline $1700-1724$ & 20 \\
$1725-1749$ & 24,2 \\
$1750-1774$ & 14,9 \\
$1775-1799$ & 14,8 \\
\hline Total media & 18,4 \\
\hline
\end{tabular}

Fuente: Archivos Parroquiales de San Pedro de Valderaduey, Arenillas y Vallecillo.

Gráfico 4. Duración media de los matrimonios $2^{\mathrm{a}}$ nupcias.

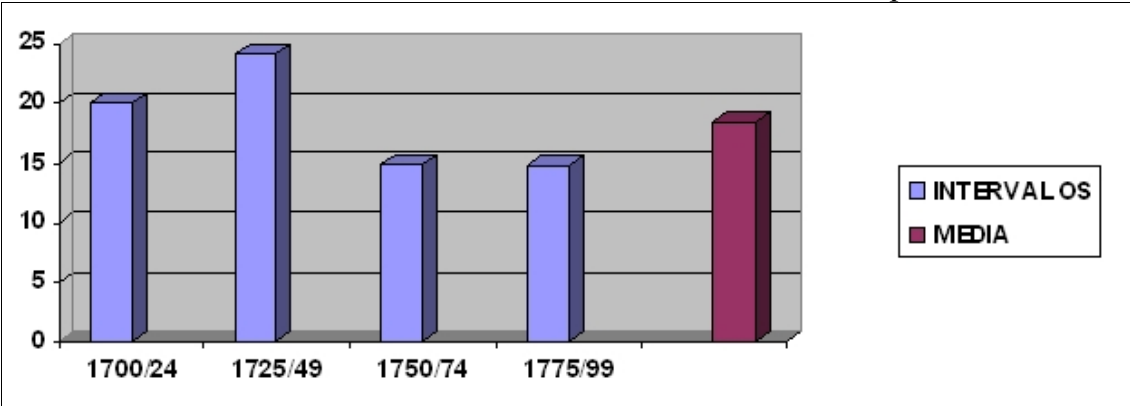

FuENTE: Archivos Parroquiales de San Pedro de Valderaduey, Arenillas y Vallecillo.

Por lo que respecta a los matrimonios de segundas nupcias, la duración media se sitúa en los 18,4 años, inferior que en los de $1^{a}$ nupcias, ya que, la edad de los cónyuges de este segundo matrimonio es más elevada de lo que lo había sido en una primera unión. A pesar de todo, es una media bastante alta, sobre todo en la primera mitad del siglo XVIII, llegando a superar los 24 años, ya que más del 50\% de las parejas se casan con menos de 24 años. Sin embargo en la segunda mitad cae hasta los 14 años siendo inferior que la media de todo el siglo. Este descenso le podemos poner en relación con el aumento en la edad de los cónyuges que acceden

${ }^{49}$ Esta estabilidad contrasta con otras zonas donde se producen diferencias más importantes como la montaña noroccidental leonesa donde se produce una divergencia de 2 años entre la primera mitad de siglo y la segunda mitad. Vid. Pérez Álvarez, M.J. (1996). La montaña noroccidental leonesa... op. cit. p.266. 
al matrimonio en $2^{\mathrm{a}}$ nupcias, donde un $80 \%$ de ellos lo hacen a edades superiores a 24 años ${ }^{50}$.

\section{PROCEDENCIA GEOGRÁFICA DE LOS CÓNYUGES.}

El matrimonio provoca la salida de la casa paterna y el abandono del lugar de residencia con todo lo que ese hecho lleva consigo desde un punto de vista jurídico, los derechos vecinales, como desde un punto de vista personal, nuevas relaciones intrafamiliares y de vecindad que, en muchos casos, podrán modificar las pautas de comportamiento existentes hasta ese momento. Por ello, la procedencia geográfica de los novios es un aspecto importante, no solo para estudiar la movilidad de los matrimonios, sino también para explicar gran cantidad de nuevas relaciones sociales surgidas a tal efecto.

Cuadro 14. Origen de los esposos por sexos. $1^{\text {as }}$ nupcias. 1700-1799.

\begin{tabular}{lccc}
\hline & Varón & Hembra & Total \\
\cline { 2 - 3 } & $\%$ & $\%$ & $\%$ \\
\hline Localidad donde se casan & 31,1 & 42 & 73,1 \\
Otras localidades & 17,1 & 9,8 & 26,9 \\
\hline Total & \multicolumn{2}{c}{ Varón } & Hembra \\
\hline & $\%$ & $\%$ & \\
\cline { 2 - 3 } & 64,5 & 81,1 & \\
Oocalidad donde se casan & 35,5 & 18,9 \\
\hline Total localidades & 100 & 100 & \\
\hline Fuenal & &
\end{tabular}

FUENTE: Archivos Parroquiales de San Pedro de Valderaduey, Arenillas y Vallecillo.

Según la muestra analizada, el $73,1 \%$ de los novios que acceden al matrimonio proceden de la misma localidad donde se casan y el $26,9 \%$ pertenecen a otra localidad distinta ${ }^{51}$. Por lo tanto, $3 / 4$ de los esposos que se unen en matrimonio son vecinos del pueblo donde éste se realiza, originando con ello una escasa movilidad que provoca una fuerte endogamia. Por sexos, es mayor el número total de mujeres que se casan en la parroquia donde han nacido con respecto al de los hombres ${ }^{52}$. A

${ }^{50}$ Ver cuadros 5 y 6.

51 Pero que el dato de personas autóctonas sea tan alto no quiere decir, como veremos más adelante en el cuadro 16, que se produzcan un elevado porcentaje de matrimonios donde ambos cónyuges sean de la misma parroquia, sino todo lo contrario.

${ }^{52}$ Floristan, A. (1982). La Merindad de Estella en la Edad Moderna: los hombres y la tierra. Pamplona, p. 147. 
pesar de todo, en ambos sexos es mayor el número de personas que se casan allí donde han nacido, siendo superior la hembra al varón, ya que, de todas las mujeres que se casan el $81,1 \%$ de ellas lo hacen en la parroquia donde han nacido y tan solo el $64,5 \%$ de los esposos ${ }^{53}$. A pesar de estos datos, hemos de decir que solo se refiere al origen sin más, ello no quiere decir que una vez celebrado el matrimonio se asienten definitivamente en ese lugar.

Cuadro 1. Origen de los esposos por sexos. $2^{\text {as }}$ nupcias. $1700-1799$.

\begin{tabular}{lccc}
\hline & Varón & Hembra & Total \\
\cline { 2 - 3 } & $\%$ & $\%$ & $\%$ \\
\hline Localidad donde se casan & 36,7 & 28,4 & 65,1 \\
Otras localidades & 29,8 & 5 & 34,9 \\
\hline Total & \multicolumn{2}{c}{ Varón } & Hembra \\
\hline & $\%$ & $\%$ & \\
\hline Localidad donde se casan & 55,2 & 84,9 \\
Otras localidades & 44,8 & 100,1 & \\
\hline Total & 100 & 100 & \\
\hline
\end{tabular}

FUENTE: Archivos Parroquiales de San Pedro de Valderaduey, Arenillas y Vallecillo.

En segundas nupcias, la tendencia sigue siendo la misma, es decir, mayor porcentaje de esposos que proceden de la localidad donde se casan, aunque el porcentaje ha bajado al $65,1 \%$. A pesar todo, se considera un dato bastante alto para tratarse de segundas nupcias y pone de relieve la escasa movilidad de los contrayentes. La gran diferencia la encontramos cuando analizamos los datos por sexos. Los hombres en un $36,7 \%$ de los casos se casan en los lugares de nacimiento frente a un $28,4 \%$ de las mujeres, invirtiendo los valores de los matrimonios en primeras nupcias. Por otro lado, el $34,9 \%$ de los esposos son de otras localidades, superando los valores para las primeras nupcias. Por sexos, las mujeres mantienen valores parecidos a los que se daban en los primeros enlaces y, por su parte, los hombres tienden a aumentar aquellos que vienen de otras localidades y a disminuir los autóctonos ${ }^{54}$.

${ }^{53}$ En las bodas se sigue la tradición de celebrarlas en el pueblo de la novia, como ya veremos más adelante, por ese motivo cuando se analiza el origen de los esposos al momento del matrimonio, el porcentaje que se asigna a la mujer que se casa en la parroquia de donde es vecina, es siempre superior del que se asigna al hombre.

${ }^{54}$ Este hecho nos le vendrá a confirmar el cuadro 14. 
Cuadro 16. Evolución movilidad de los matrimonios. Ambos cónyuges solteros. 17001799 .

\begin{tabular}{crrrrr}
\hline \multirow{2}{*}{ Lugar procedencia } & -1724 & $1725-1749$ & $1750-1774$ & +1775 & Total \\
\cline { 2 - 6 } & $\%$ & $\%$ & $\%$ & $\%$ & $\%$ \\
\hline Misma localidad & 58,9 & 31,1 & 34,3 & 41,3 & 44,3 \\
Distinta localidad & 41,1 & 68,9 & 65,7 & 58,7 & 55,7 \\
\hline Total & 100 & 100 & 100 & 100 & 100 \\
\hline Distinta localidad (Km) & & & & & \\
-2 & 3,8 & 3,2 & 0 & 1 & 2 \\
$2-4$ & 26,9 & 17,7 & 24,4 & 20 & 22 \\
$4-6$ & 12,8 & 14,5 & 18,6 & 10 & 14 \\
$6-8$ & 10,3 & 16,1 & 4,7 & 11 & 10 \\
$8-10$ & 14,1 & 14,5 & 17,4 & 12 & 14 \\
$10-12$ & 9,0 & 8,1 & 4,7 & 10 & 8 \\
$12-14$ & 2,6 & 1,6 & 1,2 & 0 & 1 \\
$14-16$ & 3,8 & 0 & 4,7 & 5 & 4 \\
$16-18$ & 2,6 & 0 & 2,3 & 12 & 5 \\
+18 & 14,1 & 24,2 & 22,1 & 20 & 20 \\
\hline Total & 100 & 100 & 100 & 100 & 100 \\
\hline
\end{tabular}

FUENTE: Archivos Parroquiales de San Pedro de Valderaduey, Arenillas y Vallecillo.

Como podemos observar en el Cuadro 16 , un $44,3 \%$ de los matrimonios que se llevan a cabo en primeras nupcias para ambos contrayentes, se realizan entre personas que pertenecen a la misma parroquia. Este porcentaje se eleva hasta el $58,9 \%$ a principios de siglo para caer hasta poco más del $30 \%$ en los años centrales del siglo XVIII. Este hecho nos obliga a pensar que los jóvenes que deciden "mudar de estado" "tienden a buscar fuera de su núcleo vecinal más cercano su futura compañera, consiguiendo con ello ampliar las relaciones vecinales entre distintas localidades y cambiando las distintas formas de clientelas que dejan de circunscribirse a la localidad para ampliar su campo de acción a ámbitos en los que se interrelacionan varias parroquias cercanas. Todo esto tendrá gran importancia a la hora de establecer las diferentes relaciones sociales. Incluso se constata como las relaciones que se establecían entre las diferentes localidades se plasmaba en la repetición continua de enlaces matrimoniales entre los jóvenes de ambos pueblos, desechando pretendientes de localidades igualmente cercanas, pero que por

\footnotetext{
${ }^{55}$ Vocablo utilizado en la documentación de la época para referirse al matrimonio
} 
distintas circunstancias de afinidad clientelar, no convenía la realización del enlace ${ }^{56}$.

Además, podemos ver como la movilidad de los cónyuges en su primer matrimonio es reducida, ya que el lugar de origen de ambos contrayentes suele estar relativamente cerca, dentro de lo que se conoce con el nombre de Tierra de Campos Leonesa, por lo que los intercambios y las relaciones sociales y económicas se establecían en los entornos más próximos, aunque no en los inmediatamente aledaños ${ }^{57}$. Es interesante observar que los pueblos que están situados a menor distancia de la localidad de referencia $(0-2 \mathrm{Km})$, son los que registran un menor porcentaje de matrimonio. Esto es debido a que llega un momento en el que las intensas relaciones sociales y clientelares que, desde tiempo inmemorial, se vienen dando entre las localidades más próximas nos lleva a la imposibilidad de poder establecer algún otro tipo de vinculo o relación, obligando a los jóvenes a buscar estas relaciones en el ámbito geográfico inmediatamente siguiente $(2-4 \mathrm{Km})$. Este hecho se puede comprobar si analizamos este fenómeno a lo largo del siglo XVIII. Así observamos como, a medida que pasan los años aumenta el porcentaje de matrimonios realizados entre personas que residen entre 4-6 Km y 6-8 $\mathrm{Km}$ y desaparecen los enlaces entre personas de los núcleos más próximos. Destacan por otro lado los matrimonios que se realizan entre personas que distan entre ellas más de 18 kilómetros. Este grupo es bastante numeroso, lo que nos pone en la pista de que existe una importante movilidad entre aquellas gentes, aunque en ningún caso se producen movimientos y relaciones que rebasen la circunscripción territorial de Tierra de Campos en su sentido amplio (León, Palencia y Valladolid) ${ }^{58}$. Las personas que contraen matrimonio a estas distancias

${ }^{56}$ BARREIRo MALLON, B. (1977). "Interior y costa: dos muestras de una estructura demográfica antigua en la Galicia rural". Fuentes y Métodos. Santiago, p. 174. Dice este autor que" los verdaderos móviles tienen su origen, sin duda alguna, en las afinidades socio-económicas globales entre las parroquias, más que entre las familias y las personas individualmente. Aquellas afinidades provocan los encuentros masivos en las ferias y fiestas, originando la primera y elemental segregación social comunitaria".

57 Esto mismo pasaba en la montaña noroccidental leonesa las uniones se solían dar entre personas de localidades cercanas dentro del mismo Concejo o de uno próximo. Vid. PÉREZ Álvarez, M.J. (1996). La montaña noroccidental leonesa... op. cit. p.268.

58 No se produce grandes movimientos migratorios que podamos decir que influyan en la procedencia de los cónyuges, ya que es una comarca muy estable desde este punto de vista porque a ella no vienen personas de otros lugares de la península. En otras zonas leonesas donde la llagada de personas procedentes del resto de la península es bastante importante, como la montaña noroccidental leonesa a consecuencia de la trashumancia, el influjo de estas personas en la procedencia de los cónyuges dentro del matrimonio es muy escaso o casi inexistente. Vid. Ibidem, p.268. 
suelen ser jornaleros, en el caso de los hombres, que se desplazan por los pueblos de la comarca para ayudar en las tareas agrícolas, o personal de servicio, en el caso de las mujeres, que son requeridas en cualquier estación del año para realizar trabajos relacionados con el hogar o la ganadería, aunque el número de mujeres que abandonan sus localidades es mucho menor que el de los hombres ${ }^{59}$.

El hecho de que dos personas viudas contraigan matrimonio puede ser debido a múltiples factores: el cuidado de los hijos, sobre todo los que necesitan una atención materna más especial, aspectos económicos referentes al disfrute de los bienes una vez muerto uno de los cónyuges, etc. y puede tener como detonante una multiplicidad de intereses que van desde los puramente económicos hasta los afectivos o sentimentales.

Cuadro 17. Evolución movilidad de los matrimonios. Ambos cónyuges viudos. 1700-1800.

\begin{tabular}{crrrrr}
\hline & -1724 & $1725-1749$ & $1750-1774$ & +1775 & Total \\
\cline { 2 - 6 } \multicolumn{1}{c}{ Lugar procedencia } & $\%$ & $\%$ & $\%$ & $\%$ & $\%$ \\
\hline Misma localidad & 60 & 18,2 & 38,9 & 20 & 34,4 \\
Distinta localidad & 40 & 81,8 & 61,1 & 80 & 65,6 \\
\hline Total & 100 & 100 & 100 & 100 & 100 \\
\hline Distinta localidad (Km) & & & & & \\
-2 & 0 & 0 & 9,1 & 0 & 2 \\
$2-4$ & 50 & 11,1 & 36,4 & 18,8 & 26,2 \\
$4-6$ & 0 & 11,1 & 18,2 & 18,8 & 14,3 \\
$6-8$ & 16,7 & 22,2 & 9,1 & 12,5 & 14,3 \\
$8-10$ & 0 & 11,1 & 0 & 12,5 & 7,1 \\
$10-12$ & 0 & 11,1 & 9,1 & 12,5 & 9,5 \\
$12-14$ & 16,7 & 11,1 & 0 & 6,3 & 7 \\
$14-16$ & 0 & 0 & 0 & 0 & 0 \\
$16-18$ & 0 & 0 & 0 & 0 & 0 \\
+18 & 16,7 & 22,22 & 18,2 & 18,8 & 19 \\
\hline Total & 100 & 100 & 100 & 100 & 100 \\
\hline
\end{tabular}

FuENTE: Archivos Parroquiales de San Pedro de Valderaduey, Arenillas y Vallecillo.

Para explicar todo esto no podemos olvidarnos de los datos que nos ofrece el Censo de Floridablanca de 1787 para la zona de Tierra de Campos leonesa, cuyas

${ }^{59}$ Ver cuadro 16. 
cifras de viudedad se sitúan en torno al $5,5 \%$ de la población ${ }^{60}$. Será debido a este bajo número de viudos/as en las parroquias, el motivo por el cual, el desplazamiento a otras localidades cercanas para contraer unas $2^{\mathrm{a}}$ o $3^{\mathrm{a}}$ nupcias, sea algo necesario.

Al igual de lo que ocurría con los matrimonios donde ambos cónyuges eran solteros, serán las localidades más cercanas $(2-4 \mathrm{Km})$ las que se llevan la mayor parte de los efectivos de los viudos/as que buscan nuevo/a compañero/a. A principios de siglo la mitad de los matrimonios entre viudos se realizaban entre personas de localidades que no distaban más de $4 \mathrm{Km}$ y a finales la distancia ha aumentado hasta los 4-6 Km. Destaca la estabilidad que se produce, durante todo el siglo, de los matrimonios cuyos individuos son de pueblos que distan más de 18 $\mathrm{Km}$ y que se sitúa en valores semejantes a los que se producían cuando ambos cónyuges son solteros ${ }^{61}$.

Cuando el marido es viudo y la mujer es soltera en un $35,8 \%$ de los casos el matrimonio se realiza entre personas de la misma localidad y el 64,2\% entre personas de distinto pueblo. Por el contrario, cuando la unión es soltero-viuda el porcentaje de elegir a personas del mismo pueblo es del $65 \%$ y de distinta localidad es del $35 \%{ }^{62}$. Mayoritariamente, la mujer soltera que decide casarse con un hombre viudo prefiere hacerlo con alguno de distinta vecindad al igual que el hombre que es viudo, cuando decide casarse con una mujer soltera, lo hace con una persona ajena a su vecindad.

En ambos casos, el motivo que anima a realizar estas uniones, puede ser debido al conocimiento que ya se posee de la persona, la reputación que esta tiene en la localidad o a las distintas relaciones clientelares que se producen entre las distintas familias de las parroquias cercanas, que llevan a casar a jóvenes solteras con hombres maduros y, en muchos casos, con hijos para así recibir cuantiosas dotes proporcionadas por sus futuros maridos y que serán el sustento de dichas jóvenes una vez que ellos mueran. Cuando este hecho se produzca, la mujer pasaría a estar en el otro grupo (hombre soltero y mujer viuda) produciéndose una cambio en la tendencia. Estas jóvenes viudas, que en muchos casos quedan con hijos menores,

${ }^{60}$ Este dato está muy por debajo del número de viudos que se registran en otras zonas leonesas como la montaña noroccidental que se sitúa en un $16,2 \%$ de la población. Vid. PÉREZ ÁlvAREZ, M.J. (1996). La montaña noroccidental leonesa... op. cit. p.273.

${ }^{61}$ Ver cuadro 16.

${ }^{62}$ Destaca como tratándose de uno u otro supuesto, en el caso hombre viudo y mujer soltera $(35,8 \%$ frente a $64,2 \%)$ y hombre soltero y mujer viuda (65\% frente a $35 \%)$ los valores entre ambos son inversos en cada caso. 
en un $65 \%$ de los casos, ya no se casan con hombres solteros de otra localidad sino que deciden ir a buscar el compañero dentro de su pueblo ante la imposibilidad de que algún hombre soltero se despose con ella, porque, para éste, los beneficios que en su momento obtuvo la mujer al casarse con un hombre viudo, ahora dejan de ser tales para convertirse en una carga, ya que, en estas circunstancias (hombre solteromujer viuda), no se producen las cuantiosas dotes que beneficiaban a la mujer soltera. Por otro lado, el hombre soltero buscará esposa viuda dentro de la parroquia motivado por aspectos más relacionados con ámbitos sociales y afectivos más que puramente económicos. De este modo, cuando por parte de uno de los miembros se obtiene algún tipo de beneficio, ya sea económico, social, afectivo, etc., no se da importancia a la procedencia territorial del cónyuge siempre y cuando dicha actuación repercuta en un beneficio del matrimonio asegurando la reproducción económica y social del sistema.

Cuadro 18. Evolución movilidad de los matrimonios: viudo-soltera y soltero-viuda. 17001800 .

\begin{tabular}{crrrrrrrrrr}
\hline & \multicolumn{3}{c}{ Hombre: viudo - mujer: soltera } & \multicolumn{3}{c}{ Hombre: soltero - mujer: viuda } \\
\hline \multirow{2}{*}{ Lugar procedencia } & -1724 & $1725 / 49$ & $1750 / 74+1775$ & Total & -1724 & $1725 / 491750 / 74+1775$ & Total \\
\cline { 2 - 12 } & $\%$ & $\%$ & $\%$ & $\%$ & $\%$ & $\%$ & $\%$ & $\%$ & $\%$ & $\%$ \\
\hline Misma localidad & 23,3 & 50 & 38 & 42 & 35,8 & 88,9 & 75 & 56 & 50 & 65 \\
Distinta localidad & 76,7 & 50 & 63 & 58 & 64,2 & 11,1 & 25 & 44 & 50 & 35 \\
\hline Total & 100 & 100 & 100 & 100 & 100 & 100 & 100 & 100 & 100 & 100 \\
\hline Distinta loc. $(k m)$ & & & & & & & & & & \\
$0-2$ & 0 & 0 & 0 & 0 & 0 & 0 & 0 & 0 & 0 & 0 \\
$2-4$ & 30,4 & 0 & 20 & 15,8 & 21,3 & 0 & 50 & 0 & 0 & 7,1 \\
$4-6$ & 26,1 & 0 & 6,7 & 31,6 & 21,3 & 0 & 0 & 25 & 0 & 7,1 \\
$6-8$ & 8,7 & 50 & 6,7 & 0 & 8,2 & 0 & 0 & 0 & 0 & 0 \\
$8-10$ & 21,7 & 25 & 13,3 & 15,8 & 18,0 & 0 & 0 & 25 & 42,9 & 28,6 \\
$10-12$ & 4,3 & 25 & 6,7 & 5,3 & 6,6 & 0 & 0 & 50 & 14,3 & 21,4 \\
$12-14$ & 0 & 0 & 6,7 & 0 & 1,6 & 0 & 50 & 0 & 14,3 & 14,3 \\
$14-16$ & 4,3 & 0 & 20 & 10,5 & 9,8 & 0 & 0 & 0 & 0 & 0 \\
$16-18$ & 4,3 & 0 & 0 & 10,5 & 4,9 & 0 & 0 & 0 & 0 & 0 \\
+18 & 0 & 0 & 20 & 10,5 & 8,2 & 100 & 0 & 0 & 28,6 & 21,4 \\
Total & 100 & 100 & 100 & 100 & 100 & 100 & 100 & 100 & 100 & 100
\end{tabular}

Fuente: Archivos Parroquiales de San Pedro de Valderaduey, Arenillas y Vallecillo

En la evolución a lo largo del siglo XVIII podemos observar como, en aquellos matrimonios viudo-soltera se produce, en todo el periodo, un aumento progresivo de las uniones en las que forman parte personas de la misma parroquia cuyo cenit se sitúa a mediados de siglo. Por otro lado, los matrimonios en los que alguno de sus miembros es de distinta parroquia ve disminuir su número. De este modo, llegamos a finales de siglo con una situación bastante más equilibrada de la que 
teníamos al principio ${ }^{63}$. Todo lo contrario ocurre cuando el matrimonio de produce entre hombre soltero y mujer viuda. Es este caso, los enlaces que se producen con personas de la misma localidad tienden a disminuir y por el contrario suben aquellos que se realizan con gentes de distintos pueblos. En los matrimonios formados por viudo-soltera, hay una tendencia general a no sobrepasar los 8-10 $\mathrm{Km}$ de distancia y entre los matrimonios soltero-viuda se sobrepasan incluso los 18 $\mathrm{Km}$ de distancia, pero que en general no sobrepasa el ámbito territorial de lo que se conoce como Tierra de Campos.

\section{EL ESTADO PREVIO DE LOS CÓNYUGES.}

El estudio del estado previo de los cónyuges al matrimonio va ha constituir un aspecto esencial dentro de un análisis mucho más amplio relacionado con la familia, al tener implicaciones desde el punto de vista económico, dentro del ámbito hereditario, social, vecinal, etc. Según el cuadro 19, desde 1700-1850 el $70 \%$ de los matrimonios celebrados se realizaban en primeras nupcias entre personas solteras y el $30 \%$ en segundas nupcias para alguno o para los dos cónyuges $^{64}$. Destaca este elevado porcentaje de segundas nupcias, si bien, la ruptura de la familia por el fallecimiento de uno de sus miembros era algo muy común entre estas poblaciones, todo ello como consecuencias de la alta mortalidad que se producía entre la población adulta.

Las consecuencias eran importantes, porque una parte de la población era apartada del matrimonio tempranamente, reduciendo con ello la natalidad. Este hecho se verá atenuado gracias a que la edad al matrimonio en esta zona es una de más bajas de Castilla la Vieja ${ }^{65}$, con lo que posibilitaba la realización de varios

${ }^{63}$ Se pasa del periodo $1700-1724$ donde en el $23,3 \%$ los cónyuges son de la misma parroquia y el $76,7 \%$ de distinta al periodo $1775-1800$ donde los datos son el $42 \%$ y $58 \%$ respectivamente. Ver cuadro 18.

${ }^{64}$ Otras zonas de la provincia de León como la comarca berciana ofrece datos en las zonas rurales bastante inferiores que oscilan entre el $15 \%$ y el $17,6 \%$ con un descenso a principios del siglo $\mathrm{XX}$, al contrario de los que se producía en Tierra de Campos. Podemos comparar porcentajes similares, en torno al $30 \%$ de matrimonios en $2^{\mathrm{a}}$ nupcias, con la ciudad de Ponferrada. BARTOLOMÉ BARTOLOMÉ, J. M. (1996). Vino y viticultores en el Bierzo... Op. Cit. pp.275-276. En la zona de La Bañeza los porcentajes oscilan entre el $23 \%$ y el $26 \%$, más próximos a los de nuestra zona de estudio. Fuera de la zona leonesa los datos para Cantabria son inferiores a los de Tierra de Campos. LANZA, R. (1991). La población y el crecimiento económico de Cantabria en el Antiguo Régimen. Madrid, pp.326-330.

${ }^{65} \mathrm{La}$ edad media de los varones es de 23,8 años y de las mujeres es de 21,5 años por lo que hay una de diferencia de más de 2 años entre las edades de ambos sexos. En el Noroeste de España y el Cantábrico que superaba los 25 años de edad mientras que en Castilla la Vieja, Aragón y Cataluña lo hacían a los 23 años y a los 22 al sur del sistema Central. Por lo que respecta a la edad del varón 
matrimonios en la vida fértil de la mujer. Estas rupturas repentinas eran suplidas con nuevas nupcias ${ }^{66}$, que sufrirán diversas fluctuaciones que estarán en función de la mortalidad tanto estructural como coyuntural que se produzca en esa zona. Durante la primera mitad del siglo XVIII un $26,7 \%$ de los matrimonios se realizan en $2^{\mathrm{a}}$ nupcias y será a partir de mediados de la centuria cuando se produzca un aumento de este tipo de matrimonios hasta alcanzar el $32 \%$ un siglo después. Un $50 \%$ de los matrimonios que se realizan se producen entre viudo-soltera y solo un $24 \%$ entre soltero-viuda. Podemos deducir que, el hombre es más proclive que la mujer a realizar un segundo matrimonio, debido a que éste necesita de una esposa que se haga cargo de los hijos, si les tiene, de la casa, etc ${ }^{67}$. Además prefiere para desposarse a una soltera con el objetivo de asegurarse el cuidado de sus hijos una vez que éste muera o para que le proporcione algún vástago más que incremente su prole. La mujer, por otro lado, es mucho más reticente a volverse a casar $(24 \%)$ y cuando lo hace prefiere desposarse con un viudo ${ }^{68}$. Aunque muchas veces es la propia familia quien la lleva a ello ${ }^{69}$, otras veces es la propia viuda quien después de verse privada de su marido y, de lo que es más importante, de sus ingresos económicos se ve imposibilitada de sacar adelante a su familia y opta por contraer matrimonio de nuevo antes de intentar otras aventuras económicas como créditos o prestamos $^{70}$. Así son matrimonios donde la supervivencia está por encima de los sentimientos.

también es algo inferior pero menos acusado que en la mujer con valores que rondan los 24-25 años de edad. Ver cuadros 2 y 4.

${ }^{66}$ La reiteración de los matrimonios es el motivo que explica el elevado porcentaje de $2^{\mathrm{a}}$ nupcias.

${ }^{67}$ Esto mismo ocurre en otros lugares de la provincia de León como la Comarca de La Bañeza donde el $\mathrm{n}^{\mathrm{o}}$ de hombres que se casan en segundas nupcias es superior al de mujeres. PÉREZ RUBIO, L M. (1987). La Bañeza... Op. Cit. pp.119-121. También es similar a la zona berciana con valores que están por encima del 55\%. Vid. BARTOLOMÉ BARTOlOMÉ, J. M. (1996). Vino y viticultores... op cit. p. 276. También es muy similar al del resto de regiones españolas como Galicia y Cantabria. Vid. Barreiro Mallón, B. (1973). La jurisdicción de Xallas en el siglo XVIII. Población, sociedad y economía. Santiago. p.171. LANZA, R. (1991). La población y el crecimiento... op cit. p.332.

${ }^{68}$ En la zona berciana los datos para matrimonios entre viuda-soltero nos llevan a porcentajes que a lo largo del siglo XVIII y XIX nunca bajan del $25 \%$ en la zona rural, incluso en Los Barrios llegan al $37,4 \%$. Esto se explica por ser esta una zona de inmigración de población masculina y joven, jornaleros, que son una filón importante para las mujeres viudas. Vid. BARTOLOMÉ BARTOLOMÉ, J. M. (1996). Vino y viticultores... op cit. p. 276.

${ }^{69}$ Pérez Rubio, L M. (1987). La Bañeza... op cit. p. 121.

${ }^{70}$ Vid. Bartolomé Bartolomé, J. M. (1996). Vino y viticultores... op cit. p. 276. 
Cuadro 19. Estado previo de los cónyuges. 1700-1850.

\begin{tabular}{crrrrrrr}
\hline & $A$ & & & \multicolumn{6}{c}{$B$} \\
\hline & $N^{o}$ & $\%$ & $\%$ & $\%$ & $\%$ & $\%$ \\
\hline $1700 / 49$ & 225 & 73,3 & 26,7 & $1700 / 49$ & 55 & 25 & 20 \\
$1750 / 99$ & 264 & 68,2 & 31,8 & $1750 / 99$ & 48,8 & 22,6 & 28,6 \\
$1800 / 49$ & 293 & 67,9 & 32,1 & $1800 / 49$ & 48,9 & 24,5 & 26,6 \\
\hline Total & 782 & 69,6 & 30,4 & Total & 50,4 & 23,9 & 25,6 \\
\hline
\end{tabular}

Fuente: Archivos Parroquiales de San Pedro de Valderaduey, Arenillas y Vallecillo

\section{MOVIMIENTO ESTACIONAL DE LA NUPCIALIDAD.}

Este aspecto estaría relacionado con la proporción de matrimonios que se celebran cada mes ${ }^{71}$. Los comportamientos demográficos, en las sociedades agrarias antiguas, marcan unas pautas bastante homogéneas y características ${ }^{72}$, donde influirán aspectos muy diversos como los religiosos, climáticos, laborales, económicos, etc.

Cuadro 19. Movimiento estacional de la nupcialidad. 1700/99 (medias).

\begin{tabular}{crrrrrrrrrrrr}
\hline & $E$ & $F$ & $M$ & $A$ & $M$ & $J$ & $J$ & $A$ & $S$ & $O$ & $N$ & $D$ \\
\hline $1700 / 49$ & 236 & 171 & 122 & 67 & 130 & 67 & 114 & 33 & 92 & 33 & 101 & 41 \\
$1750 / 99$ & 182 & 244 & 46 & 102 & 160 & 94 & 144 & 30 & 24 & 38 & 126 & 23 \\
\hline Total & 205 & 206 & 78 & 81 & 142 & 92 & 127 & 37 & 58 & 41 & 108 & 34 \\
\hline
\end{tabular}

FUENTE: Archivos Parroquiales de San Pedro de Valderaduey, Arenillas y Vallecillo

Pero si nos fijamos en el calendario agrícola y religioso podemos entender los ritmos nupciales de nuestra zona de estudio. Los matrimonios describen una tendencia desigual a lo largo de los meses del año con máximos y mínimos que nos indican unas pautas socio-culturales muy definidas. En primer lugar, tenemos tres puntos donde los individuos adquieren el estado del matrimonio. El primero se produce en los meses de Enero y Febrero cuando están paradas las tareas agrícolas y el campesino dispone de más tiempo libre para acudir a fiestas ${ }^{73}$, relacionarse con

${ }^{71}$ HenRY, L. (1983). Manual de demografía Histórica. Barcelona, p.77.

72 Roger Mols, S.J. (1987). La población europea. Historia económica de Europa. Cipolla. Barcelona, pp. 51-52.

${ }^{73}$ Importante es la fiesta de Carnaval, anterior a la Cuaresma. Así Burke que el carnaval se va a convertir en una de las fiestas con mayor predominio en Europa y donde el sexo y comida, entre otras muchas actividades, serán sus aspectos más importantes. Vid. BURKE, P. (1991). La cultura popular en la Europa Moderna. Madrid, pp. 257-342. 
sus vecinos o con individuos de localidades próximas, etc. Además a concluido una de las épocas, el Adviento y la Navidad, donde los dictámenes religiosos hacían disminuir la nupcialidad en esos meses ${ }^{74}$. El segundo momento de auge matrimonial se produce entre los meses de Mayo y Julio y se debe a la finalización de la sementera de primavera y al inicio de muchas de las ferias y fiestas. Todo ello con la salvedad del descenso que se produce en el mes de Junio al anticipo de alguna de las tareas agrícolas como es la siega de los prados y de la superficie forrajera importante en esa zona ${ }^{75}$. El mes Julio ya no será capaz de recuperar los valores del mes de Mayo debido a la proximidad de las tareas agrícola de recolección. Tenemos un último repunte de la nupcialidad en el mes de Noviembre $^{76}$.

Los momentos de menor nupcialidad son tres, de los cuales dos de ellos son originados por mandatos Iglesia Católica que no celebraba matrimonios en Cuaresma (Marzo-Abril) y Adviento (Diciembre), restricciones estas que afectaron al resto de la población europea y española. Aunque en nuestra zona el descenso que originará este tipo de dictámenes religiosos no será tan importante como el ocasionado en los meses de Agosto- Octubre ${ }^{77}$ provocado por las tareas agrícolas ${ }^{78}$

${ }^{74}$ Esto mismo sucede en otras zonas como El Bierzo y La Bañeza donde será el mes de febrero el momento de mayor número de matrimonios. Vid. BARTolomé BARTOlOMÉ, J. M. (1996). Vino y viticultores en el Bierzo. Sociedad y estructuras económicas durante el siglo XVIII. Universidad de León, pp.277-278. PÉrez Rubio, L M. (1987). La Bañeza... op cit. p. 115. En la zona baja de la montaña noroccidental leonesa o submontaña de clara economía agraria con máximos en Enero y Febrero. Por el contrario en la zona alta los máximos se producen a partir de Abril hasta Agosto debido a factores climatológicos, por el regreso de los novios pastores que habían estado fuera y fin de recogida de la hierba. Vid. PÉREZ Álvarez, M.J. (1996). La montaña noroccidental leonesa... op. cit. p. 270.

75 Esta misma inflexión, aunque a menor escala, se produce en la zona baja de la montaña noroccidental leonesa, donde a pesar de los desequilibrios se mantiene hasta Julio. Vid. Ibidem, p. 270.

${ }^{76}$ Este repunte de la nupcialidad es muy común en la mayoría de las regiones leonesas y es consecuencia del final de las tareas agrícolas de recolección y vendimia y antes del Adviento. Vid. Bartolomé Bartolomé, J. M. (1996). Vino y viticultores en el Bierzo... Op. cit, p. 277, Pérez Rubio, L M. (1987). La Bañeza... op cit. p. 115, Pérez Álvarez, M.J. (1996). La montaña noroccidental leonesa... op. cit. p. 270 y también en las españolas. Vid. BARREIRO MALLÓN, B. (1973). La jurisdicción de Xallas a lo largo del siglo XVIII. Población, sociedad y economía. Santiago, p.157.

${ }^{77}$ En la zona alta de la montaña leonesa estos meses de verano serán los de mayor número de matrimonios. Vid. Pérez Álvarez, M.J. (1996). La montaña noroccidental leonesa... op. cit. p. 270.

${ }^{78}$ Por ejemplo en la Bañeza se produce el caso contrario y la mayor caída se produce en la Cuaresma. Vid. PÉrez Rubio, L M. (1987). La Bañeza... op cit. p. 116. 
de recolección en el mes de Agosto y de vendimia en el mes de Octubre ${ }^{79}$. En este intervalo de descenso de la nupcialidad se aprecia una ligera recuperación en el mes de septiembre que la podemos equiparar a la inflexión que se produce en el mes de junio. Ambas pueden ser catalogadas como fenómenos de transición entre dos momentos, uno de claro retroceso y otro de repunte matrimonial, ocasionados por el final o el inicio de tareas agrícolas ${ }^{80}$.

Gráfico 5. Movimiento estacional de la nupcialidad. 1700-1800.

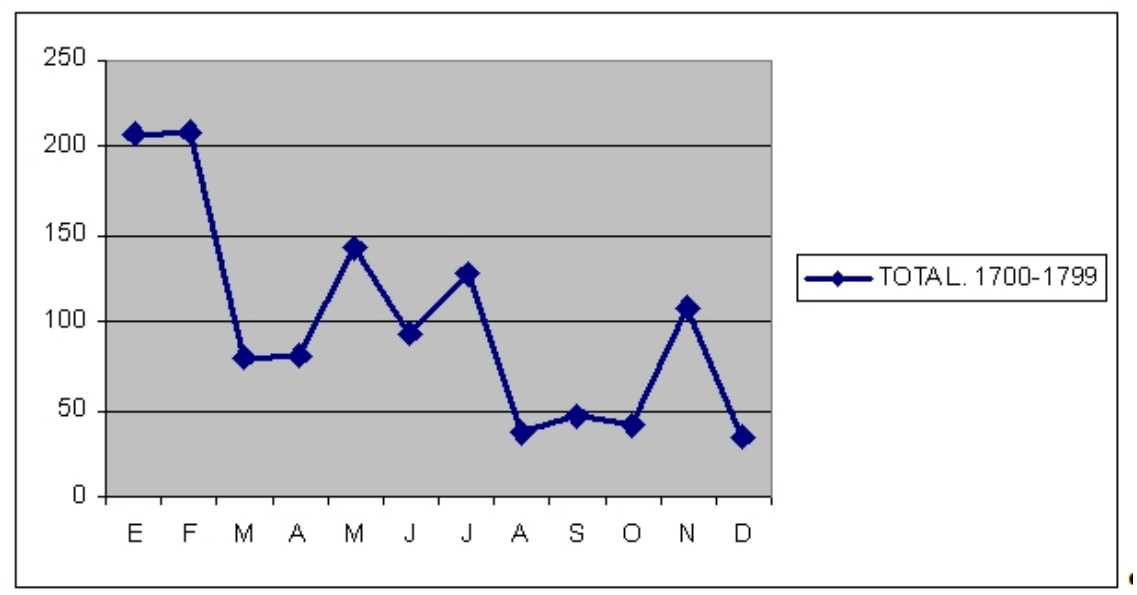

FueNTE: Archivos Parroquiales de San Pedro de Valderaduey, Arenillas y Vallecillo.

En conclusión, podemos decir que la nupcialidad pasa a ser el parámetro demográfico más importante dentro de la formación, constitución y consolidación del matrimonio y a la vez tendrá implicaciones sobre los índices de fecundidad. Además, la nupcialidad es importante cuando el acceso a la tierra se realiza por medio de la herencia familiar, con lo que la restricción del acceso al matrimonio podía ser el resultado de una conducta dirigida a evitar una elevada descendencia que llevaría a fragmentar en exceso las propiedades haciendo peligrar la continuidad social y económica del sistema. Aunque la elevada tasa de nupcialidad y la precocidad en la edad de matrimonio, sobre todo entre las mujeres, indica un

${ }^{79}$ Este descenso del mes de Octubre debido a la vendimia se produce también en el Bierzo por la misma circunstancia. Vid. BARTOlOMÉ BARTOlOmÉ, J.M. (1996). Vino y viticultores en el Bierzo... Op. cit. p. 277.

${ }^{80}$ El descenso del mes de Junio por el inicio de la siega de hierba y forrajes y el aumento del mes de Septiembre por el final de la cosecha y el inicio posterior en Octubre de la Vendimia. 
aprovechamiento al máximo de su capacidad reproductora y una escasa influencia de los diferentes condicionantes estructurales y coyunturas externos a la hora de constituir los matrimonios, formados, en su mayor parte, por personas de distintas parroquias y realizados entre individuos que acceden por primera vez al matrimonio, aunque van adquiriendo importancia aquellos que lo hacen en segundas nupcias. 